\title{
IDENTITY FEDERATION MENGGUNAKAN LDAP UNTUK PROCESS- DRIVEN APPLICATION BERBASIS JBPM : STUDI KASUS ADMINISTRASI KERJA PRAKTIK MAHASISWA
}

\author{
${ }^{1}$ I Wayan Widi Pradnyana,${ }^{2}$ lin Ernawati \\ Jurusan Sistem Informasi, Fakultas IImu Komputer, \\ Universitas Pembangunan Nasional Veteran Jakarta \\ Email : ${ }^{1}$ wayan.widi@upnvj.ac.id, ${ }^{2}$ iinernawati@upnvj.ac.id
}

\begin{abstract}
Abstrak
Aplikasi berbasis proses atau process-driven application sebagai satu jenis aplikasi untuk menjalankan prosedur operasional dalam suatu organisasi. Keterlibatan beberapa pengguna dalam uturan pelaksanaan tugas atau task terkadang terjadi proses klaim jika task tersebut ditangani oleh salah satu anggota dalam kelompok, atau delegasi ke pengguna lain untuk menimalisir tertundanya penyelesaian proses. Sebuah organisasi dapat menggunakan basis data khusus untuk manajemen identitasnya seperti teknologi LDAP yang merepresentasikan basis data hirarkis sesuai struktur organisasi, disamping itu juga memfasilitasi single sign-on untuk otentikasi. Pada tulisan ini akan dikaji penggunaan LDAP pada OpenLDAP untuk pelaksanaan proses pada BPMS berbasis JBPM. Dari beberapa pengujian fungsi, didapat bahwa LDAP dapat membantu fungsi otentikasi dan otorisasi sehingga eksekusi proses dan task dapat dilaksanakan.
\end{abstract}

Kata kunci: manajemen identitas, aplikasi berbasis proses, BPMS, JBPM, LDAP, OpenLDAP

\begin{abstract}
Process-driven application as a type of application to run operational procedures within an organization. The involvement of several users in task assignment or task sometimes occurs when the task is handled by one member in the group, or delegation to another user to minimize the delay in the completion of the process. An organization can use a special database for identity management such as LDAP technology that represents a hierarchical database according to the organizational structure, while also facilitating single sign-on for authentication. In this paper we will study the use of LDAP on OpenLDAP for implementing the process on BPPM based JBPM. From several function tests, it was found that LDAP can help authentication and authorization functions so that execution of processes and tasks can be carried out.
\end{abstract}

Keywords : identity access management, process-driven application, BPMS, JBPM, LDAP, OpenLDAP

\section{PENDAHULUAN}

Universitas Pembangunan Nasional Veteran Jakarta (UPNVJ) adalah salah satu perguruan tinggi yang termasuk melaksanakan kewajiban pengelolaan Tata Kelola Teknologi Informasi berdasarkan Peraturan Kemristekdikti [3]. Di dalam tata kelola dimaksud mencakup pengelolaan (i) arsitektur proses bisnis, (ii) arsitektur data dan informasi, (iii) arsitektur aplikasi, dan (iii) arsitektur teknologi. Perubahan bisnis yang terjadi baik dari internal dan eksternal akan dapat mempengaruhi perubahan arsitektur tersebut meliputi perubahan proses bisnis, data/informasi, aplikasi, bahkan sampai lanskap teknologi.

Stiehl [5] menawarkan konsep yang diharapkan dapat lebih sigap mengadapi 
perubahan tersebut yaitu Process-Driven Application (PDA : Process-Driven Application) menggunakan BPMN. Processdriven application memberikan penekanan metodologi top-down berbasis proses yang sangan melibatkan peran aktif business user, functional team bersama technical team, dengan penggunaan intensif BPMN (Business Process Model Notation) sebagai tata permodelan dan dan BPMS (Business Process Management System) sebagai sarana konfigurasi dan eksekusi proses dalam Process-Driven Application.
Selain itu diberikan juga konsep mengenai Process-Driven Architecture (PDAr : Process-Driven Architecture). Processdriven Application (PDA) merupakan aplikasi berorientasi bisnis yang menjamin pemisahan proses bisnis dalam cakupan fungsional, sistem, dan lingkup organisasi, dengan penggunaan kembali data dan fungsionalitas dari platform. PDAr memiliki elemen inti dari arsitektur ini adalah (i) PDA itu sendiri, (ii) service-contract, dan (iii) lapisan implementasi service-contract.. Gambar 1 berikut menjabarkan komponen dari Process-Driven Architecture.

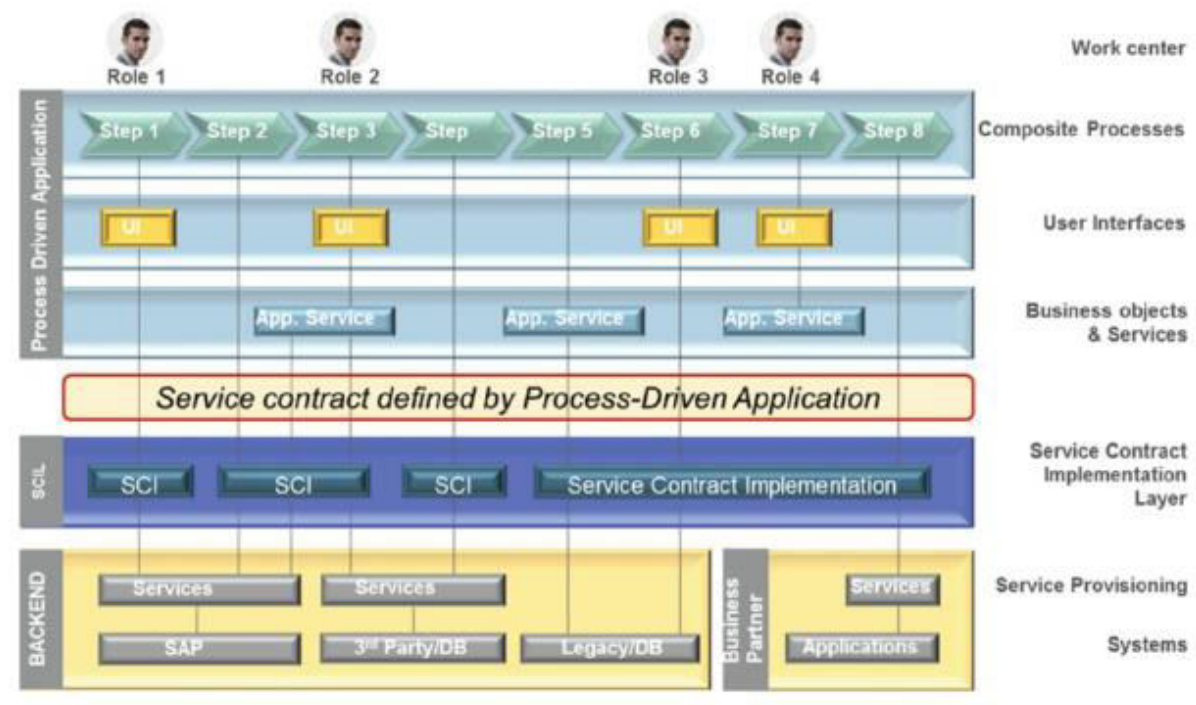

Gambar 1: Process-Driven Architecture

Rancangan yang diusulkan oleh Recupero [4] dalam arsitektur bernama Prisma Smart Urban Framework, yang ditampilkan pada Gambar mencantumkan penggunaan BPMS/BPM Engine dengan implementasi dari Jboss JBPM dan layanan LDAP dengan implementasi dari OpenLDAP. BPM Engine dengan teknologi dari Jboss jBPM sebagai process-driven application memberikan fitur dan sarana manajemen proses mencakup: desain, implementasi, simulasi, eksekusi proses, dan analitis [1] Berdasarkan konsep Identity Federation pada LDAP [2] dalam perannya memberikan akses terpusat (Centralized Model) untuk manajemen identitas dan akses (Identity Access Management) kepada pengguna untuk layanan otentikasi sertap layanan otorisasi dengan baik. 


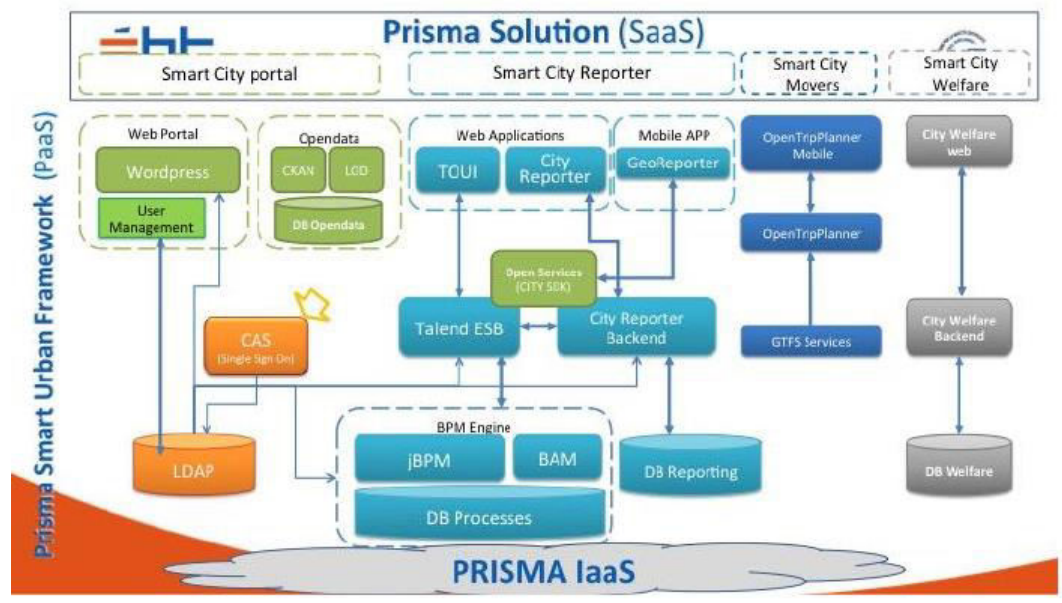

Gambar 2: Arsitektur citizen engagement platform

Dalam komponen PDA, komponen role dalam work center menunjukkan bahwa terdapat pemisahan peran dalam eksekusi composite process untuk mengakses business object. Proses identifikasi pengguna dan perannya dengan tepat sangat diperlukan agar urutan proses dapat berjalan dengan benar untuk mencapai tujuannya. Mekanisme

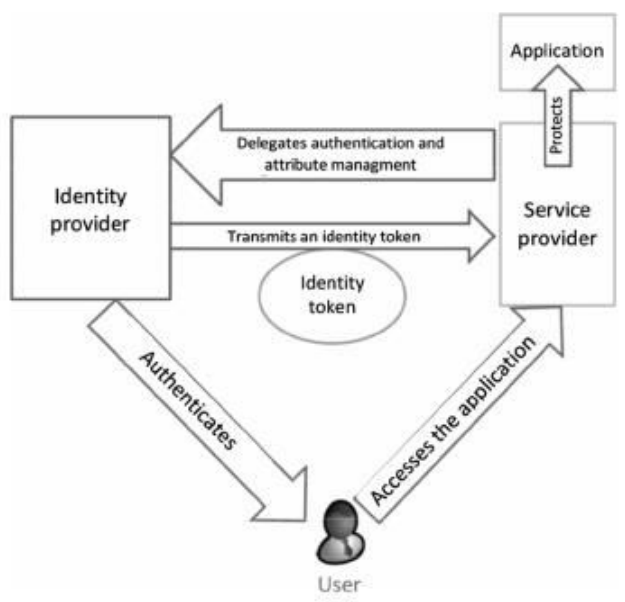

Gambar 3: Konsep Identity Federation

identifikasi pengguna dan perannya diterapkan dalam strategi Identity Federation. Berdasarkan hal tersebut, muncul pertanyaan bagaimanakah strategi penerapan manajemen identitas yang baik pada arsitektur berbasis proses diterapkan pada sebuah kasus proses bisnis. Pada artikel ini akan dibahas pelaksanaan dan evaluasi penerapan manajemen identitas dan akses kontrol menggunakan LDAP dalam arsitektur Process-Driven Application yang menggunakan JBPM. Proses bisnis yang menjadi studi kasus adalah SOP Kerja Praktik pada Fakultas IImu Komputer UPN Veteran Jakarta [6] .

\section{METODE}

Metode yang diterapkan pada penelitian ini yaitu : spesifikasi process-driven application, implementasi process-driven application, implementasi identity provider , implementasi service provider, evaluasi identity provider pada process-driven application.

Analisis proses bisnis dilakukan dengan melakukan telaah dokumen dari SOP yang telah berjalan, menerapkan metode dari Siethl [5] menjabarkan metode untuk definisi spesifikasi processdriven application yaitu sebagai berikut : (1). Define general information, (2). Define process information. (3). Define exception/event handling. (4). Define business object, (5). Define user interfaces. (6). Define services. Pada penelitian ini akan digunakan studi kasus kegiatan administrasi kerja praktik pada institusi penelitian dilakukan.

Implementasi process-driven application diterapkan pada platform BPM System dalam hal ini yaitu pada JBPM. 
Pada studi kasus ini akan di-terapkan satu proses yaitu proses pengajuan surat kerja praktik mahasiswa.

Implementasi identity provider dilakukan dengan mengimplementasikan OpenLDAP server. LDAP service akan dikonfigurasikan untuk memberikan layanan otentikasi pengguna dari hasil analisis agar dapat masuk ke BPMS, dan juga agar melayani akses ke service pada BPMS sesuai dengan role yang diberikan pada LDAP.

Implementasi service provider dilakukan dengan melakukan konfigurasi pada BPMS agar dapat melakukan query identity token serta query access authorization menuju Identity Provider. Evaluasi Identity Access Management pada Process-Driven Application dilakukan dengan Black-Box Testing, yaitu dengan melakukan uji beberapa use case yang telah didefinisikan.

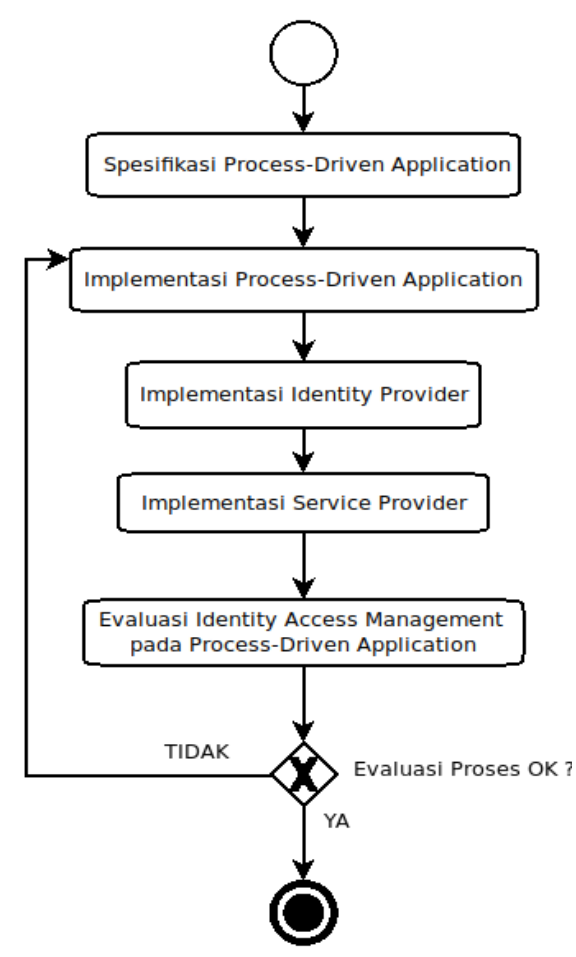

Gambar 4: Metode penelitian

\section{Spesifikasi Process-Driven Application}

Dari hasil telaah dokumen dihasilkan spesifikasi sebagai berikut :

\section{a. general information}

Disini didefinisikan bahwa proses dimulai dengan kondisi : (i) time : diinisiasi secara manual oleh seorang mahasiswa, (ii) condition : mahasiswa telah memiliki rencana kerja praktik, (iii) message : tidak ada pesan dari proses lain yang ditunggu proses ini, (iv) event : tidak ada kejadian proses lain yang memicu

b. process information

Disini didefinisikan mengenai proses : (i) pool/lane : tidak ada proses paralel, (ii) user task : draft surat pengajuan kp (actor id : mahasiswa initiator, group id : prodi mahasiswa), submit surat pengajuan $\mathrm{kp}$ (actor id : mahasiswa initiator), review surat pengajuan $\mathrm{kp}$ (actor id : dosen wali mahasiswa), approve surat pengajuan $\mathrm{kp}$ (group id : fakultas wadek 1, delegate : ketua jurusan), release surat pengajuan $\mathrm{kp}$ (group id : fakultas tata usaha), print surat pengajuan $\mathrm{kp}$ (actor id : mahasiswa initiator).

\section{c. exception event/handling}

Saat ini baru didefinisikan exception handling berupa : delegasi sebuah task secara manual dari seseorang ke orang lain, dengan harapan bahwa proses tidak menunggu lama.

\section{d. business object}

Disini didefinisikan sebuah business object yaitu : EkpSuratPengajuan, dengan atribut sebagai berikut : mahasiswaNama, mahasiswaNim, mahasiswaUserld, dosenWaliNama, dosenWaliUserld, programStudild, programStudiNama, periodeKpSemester, periodeKpTahun, bidangKerjaKp, topikKerjaKp, perusahaanAlamat, perusahaanNama, codeReleaseSuratPengajuan, commentApproveSuratPengajuan, commentReviewSuratPengajuan, commentSubmitSuratPengajuan, confirmApproveSuratPengajuan, confirmReviewSuratPengajuan, confirmSubmitSuratPengajuan.

\section{e. user interfaces}

Disini didefinisikan beberapa user interfaces berupa JBPM Form : Form Draft Surat KP, Form Submit Surat KP, Form Review Surat $K P$, form Approve Surat $K P$, 
form Release Surat $K P$, form Print Surat $K P$.

\section{f. services}

Disini belum didefinisikan service yang akan dilibatkan oleh process-driven

Tabel 1: Spesifikasi untuk permodelan proses praktik.

\begin{tabular}{|c|c|c|c|c|c|}
\hline \multirow[t]{2}{*}{ No } & \multirow[t]{2}{*}{ Komponen Proses } & \multicolumn{2}{|r|}{ Konfigurasi } & \multirow{2}{*}{\begin{tabular}{|} 
Kompon \\
en \\
Tujuan
\end{tabular}} & \multirow[t]{2}{*}{ Keterangan } \\
\hline & & Properti & Nilai & & \\
\hline 1 & Start & Type & Normal & 2 & \\
\hline 2 & $\begin{array}{c}\text { Draft - Surat } \\
\text { Pengajuan KP }\end{array}$ & $\begin{array}{c}\text { Actor ID } \\
\text { Group ID } \\
\text { Dosen Wali ID }\end{array}$ & $\begin{array}{c}\text { initiator } \\
\text { prodi.mahasiswa } \\
\text { \$dosen.wali.id }\end{array}$ & 3 & $\begin{array}{c}\text { Group mahasiswa := farhan.farid, } \\
\text { khairul.anwar } \\
\text { Group dosen wali:=wayan.widi, } \\
\text { bambang.tri }\end{array}$ \\
\hline 3 & $\begin{array}{l}\text { Submit - Surat } \\
\text { Pengajuan KP }\end{array}$ & Actor ID & initiator & 4 & farhan.farid, khairul.anwar \\
\hline \multirow[t]{2}{*}{4} & Decision & Default & If confirm Submit = true & 5 & \\
\hline & & Alternative & If confirm Submit = false & 3 & \\
\hline 5 & $\begin{array}{l}\text { Review - Surat } \\
\text { Pengajuan KP }\end{array}$ & $\begin{array}{l}\text { Actor ID } \\
\text { Group ID }\end{array}$ & $\begin{array}{c}\text { \$dosen.wali.id } \\
\text { dari task Draft - Surat Pengajuan KP }\end{array}$ & 6 & \\
\hline \multirow[t]{2}{*}{6} & Decision & Default & If confirm Review = true & 7 & \\
\hline & & Alternative & If confirm Review = false & 3 & \\
\hline 7 & $\begin{array}{c}\text { Approve - Surat } \\
\text { Pengajuan KP }\end{array}$ & Group ID & Fakultas Wadek 1 & 8 & $\begin{array}{c}\text { Group Wadek := kraugusteeliana, } \\
\text { titin.harsono }\end{array}$ \\
\hline \multirow[t]{2}{*}{8} & Decision & Default & If confirm Approve= true & 9 & \\
\hline & & Alternative & If confirm Approve = false & 3 & \\
\hline 9 & $\begin{array}{l}\text { Release - Surat } \\
\text { Pengajuan KP }\end{array}$ & Group ID & Fakultas tata usaha & 10 & $\begin{array}{c}\text { Group tata usaha := } \\
\text { suryadi, rahman }\end{array}$ \\
\hline 10 & $\begin{array}{c}\text { Print - Surat } \\
\text { Pengajuan KP }\end{array}$ & & Prodi mahasiswa & 11 & farhan.farid, \\
\hline 11 & End & Type & Normal & & \\
\hline
\end{tabular}

Implementasi Process-Driven Application beberapa object yaitu : (i) Process, (ii) Business

Implementasi proses diterapkan pada

application, karena definisi domain belum ditentukan untuk proses administrasi kerja object/model , (iii) User interfaces. JBPM dengan membuat sebuah project dengan

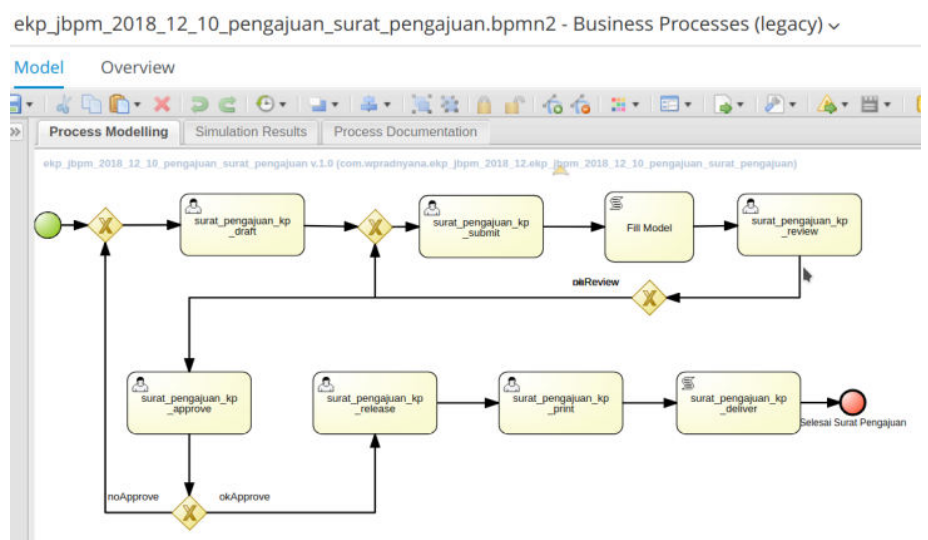

Gambar 5: Implementasi Proses Surat Pengajuan Kerja Praktik 
$\begin{array}{ccr}\text { JBPM } & \text { memiliki fasilitas } \\ \text { pengelolaan role beserta akses }\end{array}$ kontrolnya pada sistem. Berdasarkan tinjauan pada sistem JBPM, didapatkan terdapat beberapa role yang didefinisikan yaitu : kie-server, processadmin, manager, analyst, developer, dan user. Pengelolaan hak akses terhadap fasilitas masing-masing role didefinisikan dalam manajemen role pada sistem. . Adapun role User memiliki kontrol akses ke beberapa resource yaitu : home(read), process instance(read), processdefinition(read), process-reports (read), task-reports (read), task-inbox(read).

Tabel 2: JBPM System Role Access Matrix

\begin{tabular}{|c|c|c|c|c|c|c|c|c|c|c|c|c|c|c|c|c|}
\hline & \multicolumn{16}{|c|}{ Page-Resource } \\
\hline Actor id & \multicolumn{16}{|c|}{ 오 토 } \\
\hline Kie-server & & & & & & & & & & & & & & & & \\
\hline Process-admin & $\mathrm{R}$ & & $\mathrm{R}$ & $\mathrm{R}$ & $\mathrm{R}$ & $\mathrm{R}$ & $\mathrm{R}$ & & $\mathrm{R}$ & $\mathrm{R}$ & $\mathrm{R}$ & $\mathrm{R}$ & & & & \\
\hline Manager & $R$ & & & & & & & & & & $R$ & $R$ & & & & \\
\hline Analyst & & & $\mathrm{R}$ & $\mathrm{R}$ & & & & & $R$ & & & & $R$ & $R$ & $R$ & $\mathrm{R}$ \\
\hline Developer & & & & & & & $\mathrm{R}$ & & $\mathrm{R}$ & & & & $\mathrm{R}$ & & $\mathrm{R}$ & $\mathrm{R}$ \\
\hline User & $\mathrm{R}$ & & & & $R$ & $\mathrm{R}$ & & & & $\mathrm{R}$ & $\mathrm{R}$ & $\mathrm{R}$ & & & & \\
\hline
\end{tabular}

Dalam rangka kebutuhan

penggunaan user, diperlukan

Tabel 3: Pemetaan System Role

\begin{tabular}{|c|c|c|c|}
\hline No & Group Id & System Actor Id & Business Actor Id \\
\hline 1 & Kie-server & Samplekieadmin & \\
\hline 2 & Processadmin & Samplekieprocess & wahyono.tri \\
\hline 3 & Manager & Samplemanager & \\
\hline 4 & Analyst & Sampleanalyst & Semua Business Role \\
\hline 5 & Developer & Sampledevleoper & \\
\hline 6 & User & Sampleuser & \\
\hline
\end{tabular}

\section{Implementasi Identity Provider}

$\begin{array}{cr}\text { Pada server } & \text { OpenLDAP } \\ \text { diimplementasikan dengan sebuah }\end{array}$ RoorDN, sebagai contoh : $d c=x x x x x$, $d c=c o m$. Selanjutnya dibuatkan 2 node umum yaitu ou=users, dan ou=roles. Node Roles digunakan sebagai kelompok didefinisikannya jenis-jenis peran sesuai hasil analisis. Node-node yang diterapkan pada subtree ini disarankan dengan flat. Node Users digunakan untuk menampung informasi-informasi pengguna yang akan menggunakan sistem.

Obyek otorisasi pada LDAP diterapkan dengan membuat obyek groupOfNames pada LDAP. Role yang dibuat sesuai dengan hasil analisa sebelumnya, yaitu beberapa role untuk system role dan business role.

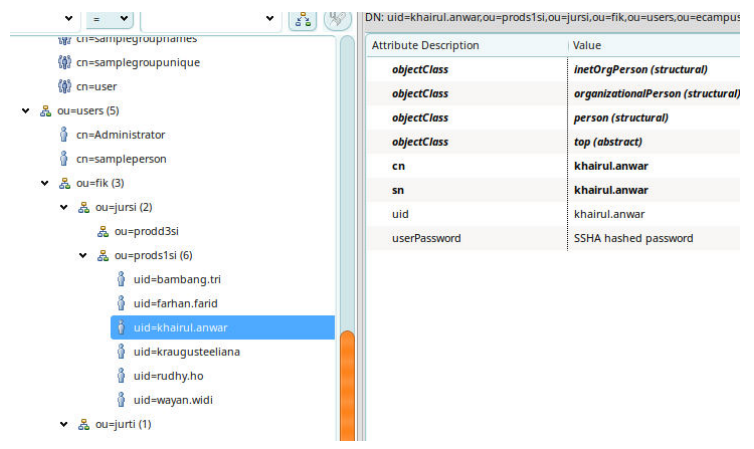

Gambar 6: Authentication Object / Actor Id

Konfigurasi pada application server dilakukan pada beberapa komponen yaitu : file standalone.xml pada section 
authentication domain dan runtime properties agar memfasilitasi authentikasi menggunakan layanan LDAP yang sudah dikonfigurasikan sebelumnya.

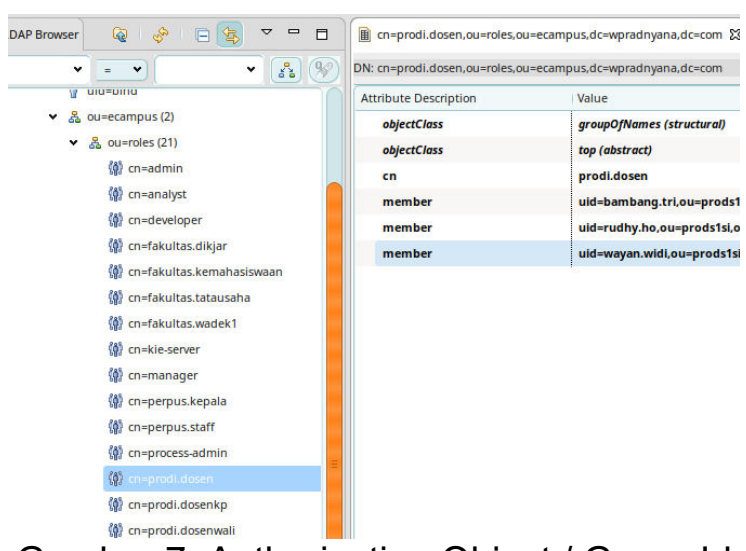

Gambar 7: Authorization Object / Group Id

\section{Implementasi Service Provider}

Implementasi peran Service

Provider diimplementasikan pada fitur yang mengelola proses autentikasi dan otorisasi pada server aplikasi JBoss Wildfly dan modul aplikasi kie-server.war dan. Berdasarkan manual pada dokumentasi Redhat BPM Suite (Sheldon, 2017) Pada module kie-server.war dikonfigurasikan pada file jbpm.user.info.properties dan jbpm.usergroup.callback.properties. Pada server aplikasi Jboss Wildfly dikonfigurasikan file standalone.xml pada section properties dan subsystem urn:jboss:domain:security. Pada subsystem urn:jboss:domain:security ditambahkan security domain Idap dengan bantuan modul

\section{org.jboss.security.auth.spi.LdapExtLogi} nModule . Pada section properties ditambahkan informasi Idap untuk org.jbpm.ht.callback dan

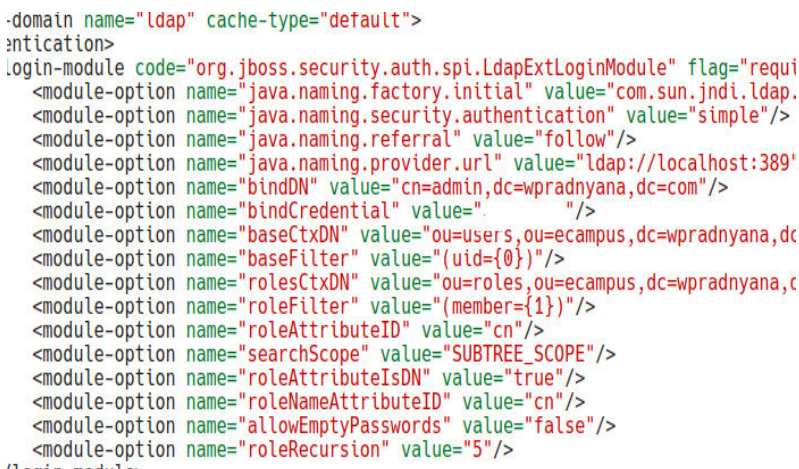

Gambar 8: Konfigurasi JBPM Server

<property name="org. jbpm.ht.admin. group" value="admin"/> <property name="org. jbpm. task. cleanup.enabled" value="false"/>

<property name="org. kie. server. persistence.ds" value=" java: jboss/datasour <property name="org. uberfire. domain" value="ldap" />

<property name="org. jbpm.ht. callback" value="ldap"/>

<property name="org.jbpm. ht. userinfo" value="ldap"/>

$<$ property name="org. kie. server. bypass. auth. user" value="false"/>

$<$ property name="org. kie.server. user" value="kieserver"/>

<property name="org.kie. server. pwd" value=' .. " "/>

$<$ property name="org. kie. server. controller. user" value="kieserver"/> $<$ property name="org. kie. server . controller. pwd" value $=$ '

Gambar 9: Konfigurasi KIE Process Service

\section{Uji Otentikasi dan Otorisasi Process- Driven Application}

Setelah proses konfigurasi diterapkan, selanjutnya dilakukan evaluasi data dan proses yang telah didefinisikan sebelumnya. Evaluasi dilakukan untuk menguji kegiatan proses manajemen identitas mencakup : authentication, authorization, dan accounting.

$$
\text { Evaluasi proses autentikasi }
$$

dilakukan dengan proses login ke sistem dengan menggunakan akun yang telah didaftarkan pada LDAP. Setiap user yang berhasil terautentikasi akan diarahkan ke homepage masing-masing dengan evaluasi proses otentikasi, otorisasi, proses delegasi, akunting. Proses otentikasi ditunjukkan pada gambar menampilkan bahwa pada Task Inbox seorang user mahasiswa terdapat sebuah task yang dapat diklaim untuk dieksekusi (claim), ataupun pantau status proses (View Process). 
(a)

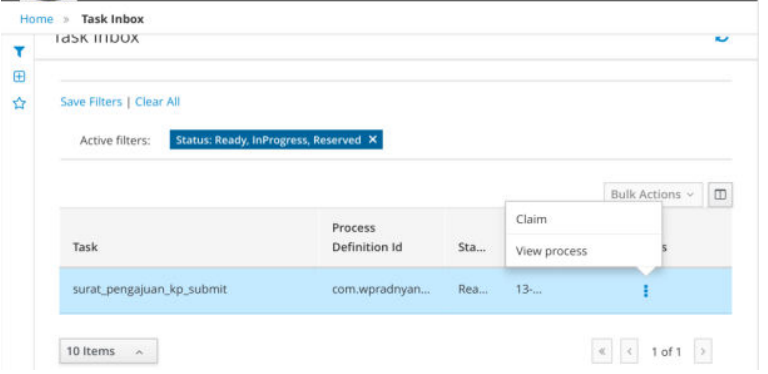

Gambar 10: Task inbox Valid user

Selanjutnya dilakukan uji proses delegasi task. Pada gambar 11 JBPM menyediakan fasilitas delegasi jika sebuah task yang ditunggu tidak kunjung dieksekusi oleh seorang actor pada suatu group.

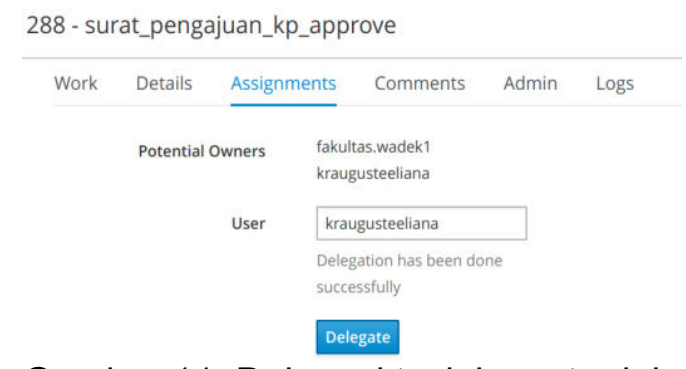

Gambar 11: Delegasi task ke actor lain

\section{Tasks By Status}

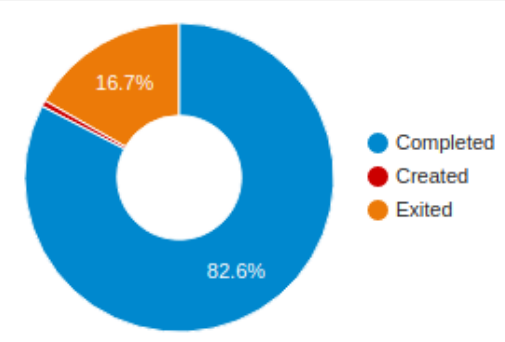

Gambar 12: Completion oleh User pada BAM

Dari beberapa percobaan yang dilakukan, semua proses instance dapat dilakukan dengan baik oleh actor tanpa mengalami kendala dalam proses otentikasi maupun otorisasi. Hal ini nampak pada Gambar 12 yang menyajikan ringkasan eksekusi proses berupa jumlah task yang berhasil dieksekusi, disajikan pada fitur Business Activity Monitoring / BAM dari JBPM.

\section{HASIL DAN PEMBAHASAN}

Pada tabel 4 berikut disampaikan hasil uji-coba evaluasi otentikasi dan otorisasi dengan melakukan eksekusi model proses bisnis yang sudah diimplementasikan pada BPMS. Eksekusi proses bisnis dilakukan pada beberapa perulangan dengan menguji case-case yang negatif, dari use case login ke sistem, inspeksi menu tersedia yang dimiliki user, eksekusi task yang berada pada task inbox user tersebut, sampai proses selesai dengan status Completed.

Tabel 4: Pengujian Case pada Sistem Proses Bisnis

\begin{tabular}{|c|c|c|c|c|c|c|}
\hline & \multirow[t]{2}{*}{ Case } & \multicolumn{2}{|r|}{ Skenario } & \multirow[t]{2}{*}{ Ekspektasi } & \multirow[t]{2}{*}{ Hasil } & \multirow[t]{2}{*}{ Keterangan } \\
\hline & & Variabel & Data & & & \\
\hline 1 & Login & Login credential & $\begin{array}{l}\text { Akun yang tidak ada dalam } \\
\text { LDAP }\end{array}$ & $\begin{array}{l}\text { Tidak berhasil } \\
\text { login. Invalid } \\
\text { credential }\end{array}$ & Valid & \\
\hline & & Login credential & Akun yang ada dalam LDAP & Tidak berhasil & Valid & Informasi login ke \\
\hline
\end{tabular}




\begin{tabular}{|c|c|c|c|c|c|c|}
\hline & \multirow[t]{2}{*}{ Case } & \multicolumn{2}{|r|}{ Skenario } & \multirow[t]{2}{*}{ Ekspektasi } & \multirow[t]{2}{*}{ Hasil } & \multirow[t]{2}{*}{ Keterangan } \\
\hline & & Variabel & Data & & & \\
\hline & & & & $\begin{array}{l}\text { login. Not } \\
\text { Authorized }\end{array}$ & & $\begin{array}{l}\text { JBPM harus } \\
\text { ditambahkan ke } \\
\text { group Uer. }\end{array}$ \\
\hline & & Login credential & $\begin{array}{l}\text { Akun yang ada dalam LDAP } \\
\text { dan dikonfigurasi dengan } \\
\text { benar }\end{array}$ & $\begin{array}{l}\text { Berhasil login. } \\
\text { Mendarat pada } \\
\text { page role User }\end{array}$ & Valid & \\
\hline 2 & Task Draft & Login credential & $\begin{array}{l}\text { Akun dari group non- } \\
\text { mahasiswa }\end{array}$ & $\begin{array}{l}\text { Tidak bisa } \\
\text { melakukan draft }\end{array}$ & Valid & $\begin{array}{l}\text { Karena task ini } \\
\text { didefiniskan untuk } \\
\text { Group Id : } \\
\text { prodi,mahasiswa }\end{array}$ \\
\hline & & Login credential & Akun dari group mahasiswa & $\begin{array}{l}\text { Bisa melakukan } \\
\text { task draft }\end{array}$ & Valid & \\
\hline 3 & Task Submit & Login credential & $\begin{array}{l}\text { Akun dari group } \\
\text { mahasiswa,namun yang } \\
\text { tidak melakukan Task } \\
\text { Draft }\end{array}$ & $\begin{array}{l}\text { Tidak bisa submit } \\
\text { dokumen yang } \\
\text { tidak dibuat }\end{array}$ & Valid & $\begin{array}{l}\text { Karena Task ini } \\
\text { didefinisikan spesifik } \\
\text { Actorld = } \\
\text { mahasiswaUserld, } \\
\text { bukan dengan Group } \\
\text { Id }\end{array}$ \\
\hline & & Login credential & $\begin{array}{l}\text { User dari group mahasiswa, } \\
\text { yang melakukan Task Draft }\end{array}$ & $\begin{array}{l}\text { Bisa melakukan } \\
\text { submit }\end{array}$ & Valid & \\
\hline 4 & $\begin{array}{l}\text { Task } \\
\text { Review }\end{array}$ & Login credential & $\begin{array}{l}\text { Salah satu user dengan } \\
\text { group dosen yang tidak di- } \\
\text { assign pada Task Draft }\end{array}$ & $\begin{array}{l}\text { Tidak bisa } \\
\text { melakukan } \\
\text { Review }\end{array}$ & Valid & $\begin{array}{l}\text { Karena task ini } \\
\text { diassign khusus } \\
\text { kepada dosen.wali.ID } \\
\text { yang ditentukan pada } \\
\text { skenario 2B }\end{array}$ \\
\hline & & Login credential & $\begin{array}{l}\text { Salah satu user dari role } \\
\text { group dosen yang di-assign } \\
\text { pada Task Draft }\end{array}$ & $\begin{array}{l}\text { Bisa melakukan } \\
\text { Review }\end{array}$ & Valid & \\
\hline \multirow[t]{2}{*}{5} & $\begin{array}{l}\text { Task } \\
\text { Approve } \\
\text { Delegation }\end{array}$ & Delegation Target & $\begin{array}{l}\text { User dari group Fakultas } \\
\text { Wadek } 1 \text { ke user lain } \\
\text { dengan group yang sama }\end{array}$ & $\begin{array}{l}\text { Bisa melakukan } \\
\text { Task Approval }\end{array}$ & Valid & \\
\hline & & Delegation Target & $\begin{array}{l}\text { User dari group Fakultas } \\
\text { Wadek } 1 \text { ke user lain } \\
\text { dengan group yang } \\
\text { berbeda }\end{array}$ & $\begin{array}{l}\text { Bisa melakukan } \\
\text { Task Approval }\end{array}$ & Valid & \\
\hline 6 & $\begin{array}{l}\text { Task } \\
\text { Release }\end{array}$ & Login credential & $\begin{array}{l}\text { User dengan group yang } \\
\text { sama }\end{array}$ & $\begin{array}{l}\text { Bisa melakukan } \\
\text { Task Release }\end{array}$ & Valid & \\
\hline \multirow[t]{2}{*}{7} & Task Print & Login credential & $\begin{array}{l}\text { User yang tidak melakukan } \\
\text { Task Draft }\end{array}$ & $\begin{array}{l}\text { Tidak bisa } \\
\text { melakukan Task } \\
\text { Print }\end{array}$ & Valid & \\
\hline & & Login credential & $\begin{array}{l}\text { User yang melakukan Task } \\
\text { Draft }\end{array}$ & $\begin{array}{l}\text { Tidak bisa } \\
\text { melakukan Task }\end{array}$ & Valid & \\
\hline
\end{tabular}

\section{SIMPULAN}

Berdasarkan hasil pengujian proses otentikasi, otorisasi, dan eksekusi task yang pada studi kasis, dapat diambil beberapa kesimpulan yaitu : bahwa penggunaan LDAP untuk manajemen identitas dalam aplikasi berbasis proses atau BPMS dapat diterapkan pada suatu organisasi. Manajemen identitas berbasis LDAP memiliki fasilitas representasi model organisasi hirarkis bisa menyesuaikan dengan struktur model orgaisasi. Penggunaan teknologi dan protokol LDAP sebagai sumber daya dan komunikasi 
otentikasi memberikan potensi BPMS terintegrasi dengan sistem lain dalam koordinasi pemenuhan tujuan proses.

Keterbatasan dalam penelitian ini yaitu pengujian masih dalam sebuah organisasi sederhana, dan masih memiliki peluang bagaimana strategi penerapannya dalam organisasi yang memiliki tantangan lebih kompleks, misalnya : integrasi dengan manajemen identitas lainnya. Di samping itu penerapan otorisasi terintegrasi antara beberapa microservices masih perlu dilakukan pengujian lebih lanjut.

\section{UCAPAN TERIMAKASIH}

Terima kasih diucapkan kepada Ketua LPPM Universitas Pembangunan Nasional Veteran Jakarta atas bantuannya dalam pendanaan penyelenggaraan penelitian ini, demikian pula kepada Fakultas IImu Komputer yang menjadi obyek studi kasus pembahasan penelitian ini.

\section{REFERENSI}

[1] JBoss jBPM team. (2017). jBPM Documentation. Retrieved from https://docs.jboss.org/jbpm/release/ 7.1.0.Final/jbpmdocs $/ \mathrm{html}$ single/\#_service_task

[2] Laurent, M., \& Bouzefrane, S. (2015). Digital Identity Management. Digital Identity Management.
https://doi.org/10.1016/C2015-000282-9

[3] Menteri Riset, Teknologi, dan Pendidikan Tinggi, R. I. Tata Kelola Teknologi Informasi di Lingkungan Kementrian Riset, Teknologi, dan Pendidikan Tinggi, Pub. L. No. NOMOR 62 TAHUN 2017, 27 (2017).

[4] Reforgiato Recupero, D., Castronovo, M., Consoli, S., Costanzo, T., Gangemi, A., Grasso, L., ... Spampinato, E. (2016). An Innovative, Open, Interoperable Citizen Engagement Cloud Platform for Smart Government and Users' Interaction. Journal of the Knowledge Economy. https://doi.org/10.1007/s13132-0160361-0

[5] Stiehl, V., Raw, R., \& Smith, P. (2014). Process-driven applications with BPMN. Process-Driven

Applications with BPMN, 9783319072, 1-334. https://doi.org/10.1007/978-3-31907218-0

[6] Yuni Widiastiwi, S.Kom., M. S. Pedoman Kerja Praktek, Pub. L. No. UPNVJ/KP/FIK-S1TI/3/12-00, 26 (2012). Jakarta, Indonesia. 